\title{
BMJ Open Public acceptability of financial incentives for smoking cessation in pregnancy and breast feeding: a survey of the British public
}

\author{
Pat Hoddinott, ${ }^{1}$ Heather Morgan,, ${ }^{2}$ Graeme MacLennan, ${ }^{2}$ Kate Sewel, ${ }^{3}$ \\ Gill Thomson, ${ }^{4}$ Linda Bauld, ${ }^{5}$ Deokhee $\mathrm{Yi}^{6}{ }^{6}$ Anne Ludbrook, ${ }^{6}$ Marion K Campbell ${ }^{2}$
}

To cite: Hoddinott $P$, Morgan $\mathrm{H}$, MacLennan G, et al. Public acceptability of financial incentives for smoking cessation in pregnancy and breast feeding: a survey of the British public. BMJ Open 2014;4:e005524.

doi:10.1136/bmjopen-2014005524

- Prepublication history and additional material is available. To view please visit the journal (http://dx.doi.org/ 10.1136/bmjopen-2014005524)

Received 21 April 2014 Revised 22 June 2014 Accepted 24 June 2014

CrossMark

For numbered affiliations see end of article.

Correspondence to Dr Pat Hoddinott; p.m.hoddinott@stir.ac.uk

\section{ABSTRACT}

Objective: To survey public attitudes about incentives for smoking cessation in pregnancy and for breast feeding to inform trial design.

Design: Cross-sectional survey.

Setting and participants: British general public. Methods: Seven promising incentive strategies had been identified from evidence syntheses and qualitative interview data from service users and providers. These were shopping vouchers for: (1) validated smoking cessation in pregnancy and (2) after birth; (3) for a smoke-free home; (4) for proven breast feeding; (5) a free breast pump; (6) payments to health services for reaching smoking cessation in pregnancy targets and (7) breastfeeding targets. Ipsos MORI used area quota sampling and home-administered computer-assisted questionnaires, with randomised question order to assess agreement with different incentives (measured on a five-point scale). Demographic data and target behaviour experience were recorded. Analysis used multivariable ordered logit models.

Results: Agreement with incentives was mixed (ranging from $34 \%$ to $46 \%$ ) among a representative sample of 1144 British adults. Mean agreement score was highest for a free breast pump, and lowest for incentives for smoking abstinence after birth. More women disagreed with shopping vouchers than men. Those with lower levels of education disagreed more with smoking cessation incentives and a breast pump. Those aged 44 or under agreed more with all incentive strategies compared with those aged 65 and over, particularly provider targets for smoking cessation. Non-white ethnic groups agreed particularly with breastfeeding incentives. Current smokers with previous stop attempts and respondents who had breast fed children agreed with providing vouchers for the respective behaviours. Up to $£ 40$ /month vouchers for behaviour change were acceptable (>85\%).

Conclusions: Women and the less educated were more likely to disagree, but men and women of childbearing age to agree, with incentives designed for their benefit. Trials evaluating reach, impact on health inequalities and ethnic groups are required prior to implementing incentive interventions.

Trial registration number: CRD42012001980.

\section{Strengths and limitations of this study}

- This large cross-sectional survey of attitudes to incentives for smoking cessation around pregnancy and for breast feeding was conducted by an internationally recognised independent company using rigorous methods to achieve a representative sample of the British general public.

- Our multidisciplinary mixed methods approach to survey design and to investigating two behaviours concurrently, used an innovative participatory approach to incorporate service user perspectives.

- Original findings show that women and those with fewer educational qualifications are more likely to disagree with incentives, raising concerns about the implications for health inequalities, as these are intended target populations for behaviour change.

- Important limitations relate to the unknown generalisability to other countries; non-responder and selection biases; potential confounding between smoking cessation and breast feeding and other unknown confounders.

- Although we randomised the order of smoking and breastfeeding questions, further framing effects are possible particularly for the introductory statements.

\section{INTRODUCTION}

Government interventions to change lifestyle behaviours are increasingly incorporating incentives to encourage healthy choices, ${ }^{1}$ but directly paying people is seen to be the least acceptable approach, ${ }^{2}$ with minimally intrusive interventions deemed more acceptable. ${ }^{1}$ Experimental studies investigating incentives for smoking cessation in a general population show that incentive acceptability increases with effectiveness. ${ }^{3}$ Media coverage of incentive interventions tends to focus on a range of concerns including perceived unfairness to those who already make healthy choices; appearing to reward 
unhealthy behaviours; potential for abuse; opportunity costs; the need to monitor and safeguard and 'Big Brother' or 'nanny state' authoritarianism. However, incentives can demonstrate to people that they are worthy of being helped and can facilitate connections between recipients and care providers. ${ }^{4}$ Incentives addressing outcomes for children appear more acceptable than outcomes for adults. ${ }^{15}$

In the UK, there are marked inequalities in health between social groups. Incentives are one strategy that could be used to redistribute resources through targeting or proportionate universalism, ${ }^{6}$ as lifestyle behaviours that compromise health around childbirth are socially patterned ${ }^{7}$ and cluster in more disadvantaged communities. ${ }^{8}$ For example, pregnant mothers aged 20 or under are: more than five times less likely to be breast feeding at 4 months; three times more likely to smoke before or during pregnancy and are less likely to stop smoking compared with mothers aged 35 or over. ${ }^{7}$ In 2010 in the UK, the breastfeeding initiation rate was $90 \%$ for mothers in managerial and professional occupations, compared with $74 \%$ of mothers in routine and manual occupations, with a difference in smoking before or during pregnancy of $14 \%$ and $40 \%$, respectively. ${ }^{7}$ In $2010,32 \%$ of pregnant women lived in a household where at least one other person smoked during pregnancy. ${ }^{7}$

There is promising evidence supporting financial incentives for smoking cessation in pregnancy ${ }^{9-11}$ : interventions that include incentives are more effective than pharmacotherapy and/or psychosocial interventions alone. ${ }^{9}$ However, the level of the incentive and the nature of accompanying behaviour change techniques, provided alongside incentives, are likely to be confounders. ${ }^{9} 11$ Reported trials to date have small samples. ${ }^{9-11}$ In addition, important concerns about limited reach, particularly to the more marginalised in society, have been raised. ${ }^{12} 13$ There are fewer incentive trials of interventions to initiate or maintain breast feeding, ${ }^{14}$ and generalisability of support interventions to predominantly formula feeding cultures like the UK is uncertain. ${ }^{15}$

This survey aimed to investigate the public acceptability of a shortlist of promising incentive strategies for stopping smoking in pregnancy or for breast feeding. This is particularly important in countries where healthcare is state funded. The ultimate study aim was to inform the design of incentive intervention trials for smoking in pregnancy and for breast feeding and to

\section{Box 1 Definition of an incentive}

Incentives include financial (positive or negative) and nonfinancial tangible incentives or rewards. This includes free or reduced cost items that have a monetary value or an exchange value, like refreshments, baby products or services like childcare or ironing. The definition excludes intangible incentives such as supportive, motivational or persuasive relationships with professionals or peers. Incentives may be delivered directly or indirectly at local, regional or national level by organisations. improve understanding of the mechanisms of action of incentives. As this is a relatively new field of research, a broad definition of incentive was applied (box 1).

\section{METHODS}

\section{Survey design}

A shortlist of seven promising incentive strategies (box 2) had been developed prior to the survey administration, informed by evidence syntheses, input from mother and baby group members who were partners in the research and qualitative research with a range of stakeholders. ${ }^{16} \mathrm{~A}$ wide range of incentives were considered to inform the shortlist, including food vouchers; baby-related items, such as diapers; gifts; beauty treatments for the mother and incentives aimed at the partner, for example, football tickets. Incentives provided for preparatory behaviours, for example, attending a support group or one-to-one session, and unpredictable incentives like raffles, were also considered. A justification for our selected shortlist is described in detail elsewhere. ${ }^{16}$ In the survey (see Web 1 , p1-4), acceptability of the shortlisted interventions was measured on a five-point Likert style scale from strongly agree to strongly disagree. The subgroup responding strongly agree, agree or neither agree nor disagree to voucher incentives were asked whether incentives should be universally provided or to low-income women only and to choose an acceptable value $(£ 2, £ 10, £ 20, £ 40$, $£ 60, £ 80$ ) for shopping vouchers provided monthly to women who prove that they have stopped smoking or are breast feeding. The values were selected to represent the range identified in the evidence syntheses. Careful consideration was given to framing effects, as greater acceptability is reported for a reward rather than payment ${ }^{17}$ and with increased effectiveness. ${ }^{3}$

\section{Data collection}

Ipsos MORI used a controlled form of random location sampling to identify 161 geographical sites (see Web 2 ,

\section{Box 2 Shortlist of seven promising incentive strategies}

1. Shopping vouchers for women who prove that they have stopped smoking during pregnancy.

2. Shopping vouchers for a woman for 2 months after the birth of her baby if she proves that she is still not smoking.

3. Shopping vouchers for a woman for 2 months after the birth of her baby if she never lets anyone smoke in her home.

4. Shopping vouchers for women who prove that they are breast feeding for the first 6 months after birth.

5. A breast pump costing around $£ 40$ provided for free by the health service.

6. Additional funding for local health services if they reach targets for the number of women who prove that they have stopped smoking during pregnancy.

7. Additional funding for local health services if they reach targets for the number of women who prove that they are breast feeding. 
p5-6) using a method of quota sampling which has been independently evaluated. ${ }^{18}$ Trained field researchers were asked to interview five people at home from 250 addresses at each site, to obtain a nationally and regionally representative sample of adults aged 18 or over between 22 March 2013 and 15 April 2013. Interlocking quotas were set for age, sex, working status and tenure based on the known profile of Great Britain (from ONS 2011 estimates for England and Wales and from General Register Office for Scotland 2011 midyear estimates, and from National Readership Survey data). National Readership Survey profiles are commonly used for this purpose; they provide a basis for interlocking quotas, for example, sex within working status. Interviewers used Computer Assisted Personal Interviewing (CAPI) with randomisation of the order for smoking and breastfeeding incentive questions generated independently and automated using CAPI software, to investigate question order framing effects. Incentive questions were asked after the demographic questions, but before the parent, smoking and breastfeeding status questions.

\section{Statistical analysis}

An a priori target sample size of 1000 was set to allow us to estimate proportions to within 3\% margin of error with $95 \%$ level of confidence. A priori questions asked:

1. Is the acceptability of the seven shortlisted incentive strategies influenced according to age (categories 18-24, 25-34, 35-44, 45-54, 55-59, 60-64, 65 and over); sex; social grade (A and B, C1, C2, D, E); region (North, North West, Yorkshire and Humberside, East Midlands, West Midlands, East Anglia, South East, South West, London, Wales, Scotland); ethnicity (White British, Other Ethnicity); education (University, GCSE or equivalent, A-level or equivalent, no formal qualifications, still studying or other qualifications, or don't know); having children (yes, no); personal experience of smoking (never smoked, ex-smoker, current smoker-failed to stop, or no attempts to stop); had a child ever been breastfed (even if for only a day or two)?

2. What are the independent predictors of acceptability of the shortlist of incentive strategies?

3. What value of incentive is most acceptable and what are the independent predictors of the preferred incentive value?

4. Are universal incentives preferred to incentives targeted at low-income women and what are the independent predictors for preference?

Data were described using the appropriate summary statistics where relevant. Responses to the Likert style outcome survey items were summarised by number, percentage and mean, and graphed using bar charts. Responses to these outcome items were tabulated, broken down by the independent predictor variables specified above. Net agreement (agree and strongly agree) and net disagreement (disagree and strongly disagree) were also reported as number and percentage. Simple and multiple ordered logit regression models were used to determine the independent predictors of acceptability for the shortlist. The relationship between predictor and outcome variables was summarised using the OR and 95\% CIs. For the financial value and targeting of incentives to low-income women only (research questions 3 and 4), two part models were used. For research question 3, the value of incentives, a probit model was used to estimate a 'positive' response (ie, strongly agree, agree or neither agree nor disagree) and then linear regression was used to model the amount of shopping voucher acceptable conditional on a positive response. For research question 4, targeting low-income women only, a similar model was used, but as the conditional response here was dichotomous, a probit model was used instead of linear regression. In all models, the most affluent status was used as the reference category where appropriate (ie, male; white ethnicity; university qualification; social grade A or B; resident in London; no children; never smoked; child breast fed). Age was entered as 5-year categories. All analyses were performed in Stata V.13 (StataCorp. 2013. Stata Statistical Software: Release V.13. College Station, Texas, USA: StataCorp LP).

\section{FINDINGS}

The characteristics of the 1144 representatives of the British public who participated in the CAPIBUS survey and any variables with missing data are detailed in table 1 . Detailed tables reporting weighted with unweighted data are available (see Web 3).

\section{Overall acceptability of incentives}

The acceptability of the seven promising incentive strategies was mixed (figure 1 and table 2). Between $34 \%$ and $46 \%$ agreed with these incentives. Overall, the most acceptable incentive, with net agreement of $46 \%$ and net disagreement of $28 \%$, was to provide a breast pump worth $£ 40$ to help women continue breast feeding. The least acceptable incentives were shopping vouchers given to women who continue to stop smoking after birth (net agreement $37 \%$ and net disagreement $47 \%$ ) or given to women to maintain a smoke-free home (net agreement $34 \%$ and net disagreement $46 \%$ ). The general public expressed collective uncertainty about providing funding to local health service providers to meet smoking cessation in pregnancy or breastfeeding targets: just over a third of the respondents agreed and a third disagreed. Framing effects with question randomisation were observed (see Web 4, p7-8). Significantly higher agreement with all breastfeeding incentive strategies was observed when breastfeeding questions were asked before the smoking questions: vouchers for breast feeding (OR 2.00; 95\% CI 1.61 to 2.46; $\mathrm{p}<0.001$ ); a free breast pump (OR 1.32; 95\% CI 1.08 to $1.62 ; \mathrm{p}<0.008$ ) and provider incentives for breastfeeding targets (OR 


\begin{tabular}{|c|c|c|}
\hline Variable & Categories & Sample (\%) \\
\hline \multirow[t]{2}{*}{ Sex } & Male & $540(47.2)$ \\
\hline & Female & $604(52.7)$ \\
\hline \multirow[t]{7}{*}{ Age } & $18-24$ & 170 (14.9) \\
\hline & $25-34$ & 175 (15.3) \\
\hline & $35-44$ & $181(15.8)$ \\
\hline & $45-54$ & 159 (13.9) \\
\hline & $55-59$ & $72(6.3)$ \\
\hline & $60-64$ & 94 (8.2) \\
\hline & $65<$ & $293(25.6)$ \\
\hline \multirow[t]{22}{*}{ Ethnicity } & White & $985(86.1)$ \\
\hline & $\mathrm{BME}$ & 151 (13.2) \\
\hline & Refused to answer & $8(0.7)$ \\
\hline & White British & $914(79.9)$ \\
\hline & White Irish & $11(1.0)$ \\
\hline & White Gypsy/Traveller & - \\
\hline & White Other & $60(5.2)$ \\
\hline & Mixed W/B Caribbean & $3(0.3)$ \\
\hline & Mixed W/B African & $1(<0.1)$ \\
\hline & Mixed White and Asian & $3(0.3)$ \\
\hline & Mixed Other & $2(0.2)$ \\
\hline & Asian Indian & $19(1.7)$ \\
\hline & Asian Pakistani & $47(4.1)$ \\
\hline & Asian Bangladeshi & $12(1.1)$ \\
\hline & Asian Chinese & $7(0.6)$ \\
\hline & Asian Other & $13(1.1)$ \\
\hline & Black African & 26 (2.3) \\
\hline & Black Caribbean & $7(0.6)$ \\
\hline & Black Other & $2(0.2)$ \\
\hline & Arab & $4(0.4)$ \\
\hline & Other & $5(0.4)$ \\
\hline & Refused & $8(0.7)$ \\
\hline \multirow[t]{5}{*}{ Smoking status } & Never smoked & $573(50.1)$ \\
\hline & $\begin{array}{l}\text { Current smoker, tried to } \\
\text { stop smoking }\end{array}$ & $175(15.3)$ \\
\hline & $\begin{array}{l}\text { Current smoker, not } \\
\text { tried to stop smoking }\end{array}$ & $63(5.5)$ \\
\hline & Ex-smoker & $281(24.6)$ \\
\hline & Declined to answer & $52(4.6)$ \\
\hline \multirow[t]{2}{*}{ Any children } & Yes & $742(64.9)$ \\
\hline & No & $402(35.1)$ \\
\hline \multirow[t]{2}{*}{ Breast feeding } & Any children breast fed & $512(47.3)$ \\
\hline & No children breast fed & $632(52.5)$ \\
\hline \multirow[t]{5}{*}{ Education } & $\begin{array}{l}\text { GCSE/O-level/CSE/ } \\
\text { NVQ }\end{array}$ & 342 (29.9) \\
\hline & A-level or equivalent & 193 (16.9) \\
\hline & Degree/Masters/PhD & 295 (25.9) \\
\hline & No formal qualifications & $197(17.2)$ \\
\hline & $\begin{array}{l}\text { Other/Don't know/ Still } \\
\text { studying }\end{array}$ & $117(10.2)$ \\
\hline \multirow[t]{6}{*}{ Social grade } & A & $36(3.2)$ \\
\hline & $\mathrm{B}$ & $203(17.7)$ \\
\hline & C1 & 370 (32.3) \\
\hline & $\mathrm{C} 2$ & $236(20.6)$ \\
\hline & $\mathrm{D}$ & $162(14.2)$ \\
\hline & $\mathrm{E}$ & $137(12.0)$ \\
\hline
\end{tabular}

Continued

\begin{tabular}{llc} 
Table 1 & & \\
\hline Variable & Categories & Sample (\%) \\
\hline Survey region & North & $77(6.7)$ \\
& North West & $142(12.4)$ \\
& Yorks \& Humberside & $104(9.1)$ \\
& West Midlands & $109(6.5)$ \\
& East Midlands & $66(5.8)$ \\
& East Anglia & $41(3.6)$ \\
& South West & $81(7.1)$ \\
& South East & $200(17.5)$ \\
& Greater London & $149(13)$ \\
& Wales & $66(5.8)$ \\
& Scotland & $109(9.3)$ \\
\hline
\end{tabular}

$1.44 ; 95 \%$ CI 1.17 to $1.77 ; \mathrm{p}<0.001)$. Differences in agreement for all smoking cessation incentive strategies were non-significant when the smoking questions were asked before the breastfeeding questions.

\section{Independent predictors of agreement with incentives}

Table 3 describes the independent predictors of agreement with incentives. For aid of interpretation and comparison, we have summarised the ORs into groups (OR $<0.5, \geq 0.5$ to $<1.0, \geq 1.0$ to $<1.5, \geq 1.5$ to $<2.0$ and $\geq 2.0$ ). Full results tables are available (see Web 5, p9-44). Being of childbearing age (44 and under) was an independent predictor of agreement with all seven incentive strategies, with agreement generally decreasing with increased age. Agreement among the 44 and under age group compared with the 65 and over age group was strongest for provider targets for smoking cessation in pregnancy $(\mathrm{OR} \geq 2.0)$.

Women who are (or would have been when younger) the intended recipients of the vouchers were less likely to agree with any shopping vouchers for: smoking cessation during pregnancy (OR $0.71 ; 95 \%$ CI 0.57 to 0.88 ; $\mathrm{p}=0.002$ ), after birth (OR $0.68 ; 95 \%$ CI 0.55 to 0.85 ; $\mathrm{p}=0.001$ ), smoke-free homes (OR $0.72 ; 95 \%$ CI 0.58 to $0.90 ; \mathrm{p}=0.003$ ) or breast feeding (OR 0.77; 95\% CI 0.62 to $0.95 ; \mathrm{p}=0.016$ ) when compared with men.

Respondents with lower educational level, when compared with those with degree level qualifications, were more likely to disagree $(0.5 \leq \mathrm{OR}<1.0)$ with shopping voucher incentives given to women for smoking cessation before or after birth, a free breast pump or for additional funding to local health services for meeting smoking cessation targets. There was no evidence of difference across education groups for vouchers for breast feeding or additional payments to local health services for meeting breastfeeding targets.

The associations with lower social grade when compared with social grade A and B combined were less clear. Social grade E predicted agreement with shopping vouchers for smoking cessation in pregnancy (OR 1.74; 

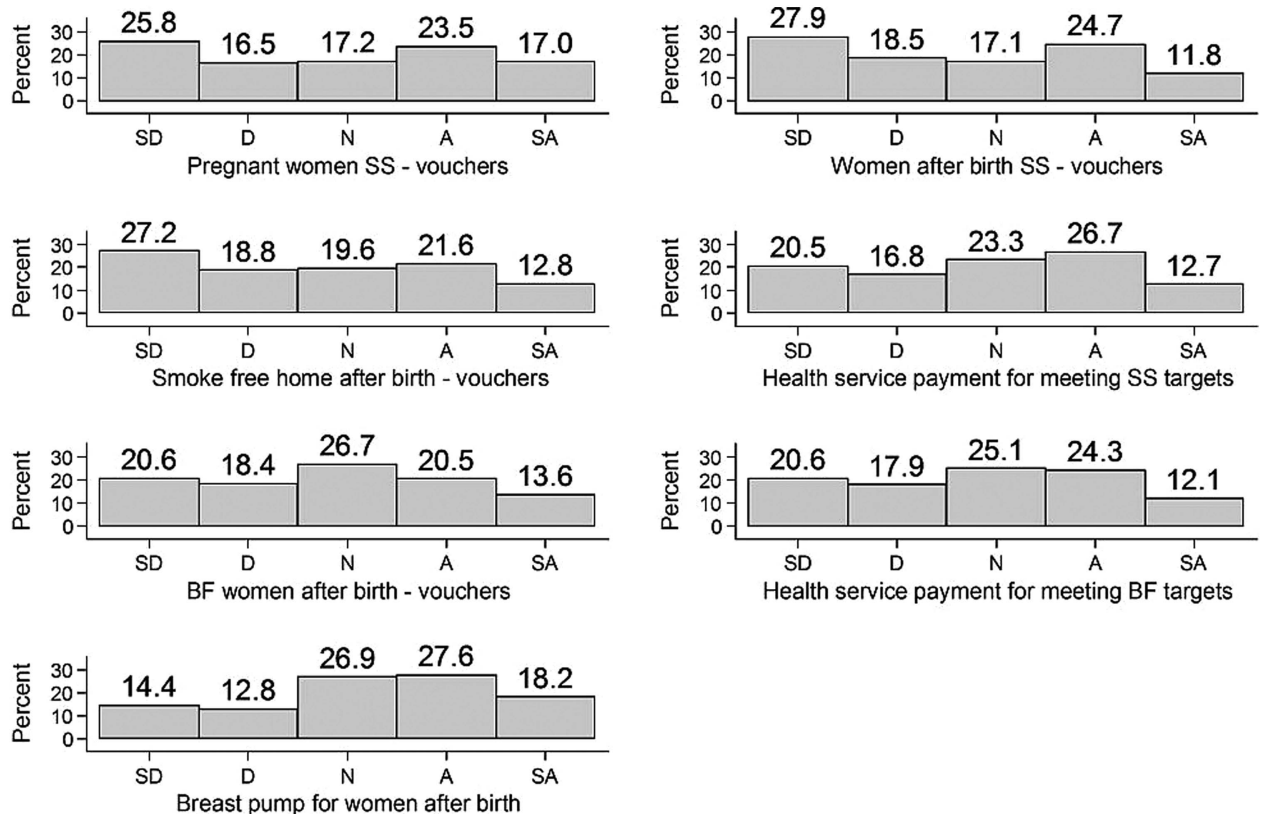

Figure 1 Bar charts of general public agreement with the shortlist of incentive strategies. SD, strongly disagree; D, disagree; $N$, neither agree nor disagree; A, agree; SA, strongly agree; BF, breast feeding; SS, stop smoking.

$95 \%$ CI 1.12 to $2.70 ; \mathrm{p}=0.014)$ and a free breast pump (OR 1.57; $95 \%$ CI 1.00 to 2.46; $\mathrm{p}=0.05$ ); social grade C2 predicted agreement with vouchers for continued smoking cessation after birth (OR 1.64; 95\% CI 1.18 to 2.27; $\mathrm{p}=0.003$ ); but in contrast, social grade C1 predicted disagreement with additional funding to local health services for meeting smoking cessation targets (OR 0.68; $95 \%$ CI 0.50 to $0.94 ; \mathrm{p}=0.019$ ).

Being from a non-white British ethnic group, when compared with being white British, was a strong predictor of agreeing with breastfeeding vouchers (OR 2.03; $95 \%$ CI 1.43 to $2.88 ; \mathrm{p}<0.001)$ and with additional funding to local health services for meeting breastfeeding targets (OR 2.31; 95\% CI 1.63 to 3.29; $\mathrm{p}<0.001$ ) but not for a free breast pump. Being from a non-white British group also predicted agreement with vouchers for stopping smoking in pregnancy (OR 1.42; 95\% CI 1.01 to $1.99 ; \mathrm{p}=0.047$ ) and a smoke-free home (OR 1.49; 95\% CI 1.06 to $2.08 ; \mathrm{p}=0.021)$.

Current smokers who had tried stopping in the past were more likely to agree with vouchers for stopping smoking in pregnancy (OR 1.63; 95\% CI 1.18 to 2.26; $\mathrm{p}=0.003)$ and for maintaining a smoke-free home after birth (OR 1.48; 95\% CI 1.08 to 2.04; $\mathrm{p}=0.016$ ), but not for continued smoking cessation after birth, or provider incentives to meet smoking cessation targets. Those with a breastfed child were more likely to agree with vouchers for breast feeding (OR 1.67; 95\% CI 1.24 to 2.25;

Table 2 Summary of general public agreement with seven incentive strategies

\begin{tabular}{|c|c|c|c|c|}
\hline Incentive strategy & Disagree (\%) & Neither (\%) & Agree (\%) & Mean \\
\hline $\begin{array}{l}\text { Shopping vouchers for women who prove that they have stopped smoking } \\
\text { during pregnancy }\end{array}$ & 42.3 & 17.2 & 40.5 & 2.9 \\
\hline $\begin{array}{l}\text { Shopping vouchers for a woman for } 2 \text { months after the birth of her baby if she } \\
\text { proves that she is still not smoking }\end{array}$ & 46.4 & 17.3 & 36.5 & 2.7 \\
\hline $\begin{array}{l}\text { Shopping vouchers for a woman for } 2 \text { months after the birth of her baby if she } \\
\text { never lets anyone smoke in her home }\end{array}$ & 46.0 & 19.6 & 34.4 & 2.7 \\
\hline $\begin{array}{l}\text { Shopping vouchers for women who prove that they are breast feeding for the } \\
\text { first } 6 \text { months after birth }\end{array}$ & 39.1 & 26.8 & 34.2 & 2.9 \\
\hline A breast pump costing around $£ 40$ provided for free on the NHS & 27.8 & 27.0 & 45.8 & 3.2 \\
\hline $\begin{array}{l}\text { Additional funding for local health services if they reach targets for the } \\
\text { number of women who prove that they have stopped smoking during } \\
\text { pregnancy }\end{array}$ & 37.2 & 23.3 & 39.4 & 2.9 \\
\hline $\begin{array}{l}\text { Additional funding for local health services if they reach targets for the } \\
\text { number of women who prove that they are breast feeding }\end{array}$ & 38.6 & 25.1 & 36.4 & 2.9 \\
\hline
\end{tabular}


Table 3 Alternative. Summary of the independent predictors of general public agreement with incentive strategies

\begin{tabular}{|c|c|c|c|c|c|c|c|}
\hline & $\begin{array}{l}\text { Age } \\
\leq 44\end{array}$ & Female & $\begin{array}{l}\text { Lower } \\
\text { education } \\
\text { level }\end{array}$ & $\begin{array}{l}\text { Social grade } \\
\text { C or below }\end{array}$ & $\begin{array}{l}\text { Non-white } \\
\text { ethnicity }\end{array}$ & $\begin{array}{l}\text { Current smoker who } \\
\text { have attempted to } \\
\text { stop }\end{array}$ & $\begin{array}{l}\text { Children } \\
\text { breast fed }\end{array}$ \\
\hline $\begin{array}{l}\text { Shopping vouchers should be provided to women who prove that } \\
\text { they have stopped smoking during pregnancy }\end{array}$ & ++ & - & - & ++ (Grade E) & + & ++ & \\
\hline $\begin{array}{l}\text { It is acceptable to provide shopping vouchers to a woman for } \\
2 \text { months after the birth of her baby if she proves that she is still } \\
\text { not smoking }\end{array}$ & ++ & - & - & $\begin{array}{l}++ \text { (Grade } \\
\text { C2) }\end{array}$ & & & \\
\hline $\begin{array}{l}\text { It is acceptable to provide shopping vouchers to a woman for } \\
2 \text { months after the birth of her baby if she never lets anyone } \\
\text { smoke in her home }\end{array}$ & ++ & - & - & & + & + & \\
\hline $\begin{array}{l}\text { Shopping vouchers should be provided to women who breast } \\
\text { feed for the first } 6 \text { months after the birth of their child }\end{array}$ & ++ & - & & & +++ & & ++ \\
\hline $\begin{array}{l}\text { A breast pump costing around } £ 40 \text { should be available for free on } \\
\text { the NHS, to help women to continue breast feeding }\end{array}$ & ++ & & - & ++ (Grade E) & & & ++ \\
\hline $\begin{array}{l}\text { Local health services should receive additional funding if they } \\
\text { reach targets for the number of women who prove that they have } \\
\text { stopped smoking during pregnancy }\end{array}$ & +++ & & - & - (Grade C1) & & & \\
\hline $\begin{array}{l}\text { Local health services should receive additional funding if they } \\
\text { reach targets for the number of women who reach targets for the } \\
\text { number of women who breast feed }\end{array}$ & ++ & & & & +++ & & \\
\hline
\end{tabular}


Table 4 Highest acceptable value of shopping voucher for women who stop smoking during pregnancy or are breast feeding

\begin{tabular}{|c|c|c|c|c|}
\hline \multirow[b]{2}{*}{ Value } & \multicolumn{2}{|c|}{$\begin{array}{l}\text { Smoking in } \\
\text { pregnancy }\end{array}$} & \multicolumn{2}{|c|}{ Breast feeding } \\
\hline & $\begin{array}{l}\text { Number } \\
\left(\mathrm{N}=660^{\star}\right)\end{array}$ & $\begin{array}{l}\text { Per } \\
\text { cent }\end{array}$ & $\begin{array}{l}\text { Number } \\
\left(\mathrm{N}=697^{\star}\right)\end{array}$ & $\begin{array}{l}\text { Per } \\
\text { cent }\end{array}$ \\
\hline$£ 2$ & 116 & 17.6 & 146 & 20.95 \\
\hline$£ 10$ & 146 & 22.1 & 150 & 21.52 \\
\hline$£ 20$ & 193 & 29.2 & 199 & 28.55 \\
\hline$£ 40$ & 115 & 17.4 & 110 & 15.78 \\
\hline$£ 60$ & 36 & 5.5 & 36 & 5.16 \\
\hline$£ 80$ & 54 & 8.2 & 56 & 8.03 \\
\hline
\end{tabular}

${ }^{*}$ Respondents from the 1144 British public participants who strongly agreed, agreed or neither agreed nor disagreed with shopping vouchers incentives.

$\mathrm{p}=0.001$ ) and with a free breast pump (OR 1.84; 95\% CI 1.36 to $2.49 ; \mathrm{p} \leq 0.001$ ), but not with provider incentives for meeting breastfeeding targets, when compared with those with children that had not been breastfed.

Where respondents did not disagree (ie, answered strongly agree, agree or neither agree nor disagree) with providing shopping vouchers as an incentive, up to $£ 40$ / month vouchers for behaviour change were acceptable (>85\%; Table 4). This was consistent for smoking cessation and breast feeding. For smoking cessation in pregnancy, being a current smoker who has tried to stop (compared with never smoked), or having a child previously breast fed (compared with no breastfed children) was correlated with a higher value of shopping voucher (see Web 5, table 15). For breast feeding, having a child previously breast fed (compared with no breastfed children) was correlated with an increased value of shopping voucher (see Web 5, table 17).

Universal provision rather than targeting low-income women was preferred by $364(55 \%)$ of the 660 who did not disagree with vouchers for smoking cessation in pregnancy, compared with $296(44.9 \%)$ who thought that vouchers should be targeted at low-income women only. Agreement with universal provision of vouchers for breast feeding was similar: $367(52.3 \%)$ compared with $330(47.4 \%)$ thought that incentives should be provided to low-income women only. Disagreement with vouchers being given to low-income women only was associated with being a woman (see Web 5, tables 16 and 18), but this was only significant for breast feeding.

\section{DISCUSSION}

In this representative British sample, public opinion regarding the acceptability of incentives for smoking cessation in pregnancy and breast feeding was mixed. Men and women of childbearing age (44 or under), and therefore representative of the target population for this behaviour change strategy, were the only independent predictor of agreement with all seven incentive strategies. Of concern, women were significantly more likely to disagree with any of the shopping voucher incentive strategies compared with men. General public respondents with lower educational level were more likely to disagree with any voucher incentives to women for smoking cessation, or with a free breast pump. Agreement appears to be strongest in non-white ethnic groups. As reported by others, ${ }^{1}$ people with direct experiences of attempting the target behaviours were more likely to agree with incentives.

This is the largest survey of public attitudes to incentive provision aiming to change lifestyle behaviours and was conducted by an independent company with an international reputation for conducting surveys of this type. Methodological research indicates that high-quality, well-controlled quota sampling in survey design has a negligible impact on the bias and precision of estimates compared with that in a simple random sample. ${ }^{18}$ Our multidisciplinary mixed methods approach to survey design and investigating two behaviours concurrently, with an innovative participatory approach to incorporating service user perspectives through coapplicant mother and baby groups located in disadvantaged areas, is novel. ${ }^{16}{ }^{19}$ Important limitations relate to the unknown generalisability to other countries; nonresponder and selection biases and other potential confounders. This research was commissioned to investigate two behaviours concurrently, and this may be considered as either a strength or a limitation. There is a tradition of researching lifestyle behaviours separately, but from an individual and a social network perspective, they are often complexly inter-related. ${ }^{7}{ }^{16}$ In addition, smoking cessation and breast feeding are associated and may confound each other, as women who stop smoking are more likely to breast feed than those who continue to smoke. ${ }^{20} 21$ The framing effects observed by randomising question order are important and further unknown framing effects could be present. In particular, the introduction contained a stronger statement about the evidence for incentives changing smoking behaviour than for breast feeding, as is consistent with current evidence $^{9-11} 14$ and evidence of effectiveness has been shown to impact on acceptability. ${ }^{3}$ We propose that more research should investigate health-related behaviours concurrently to understand their complex inter-relationships.

The implications of our findings for efforts to reduce health inequalities are important. The disagreement with incentive strategies among those with lower educational level, which is considered the strongest predictor of disadvantage, ${ }^{6}$ is unexpected and a concern as addressing health inequalities is a government priority. Smoking in pregnancy and not breast feeding are highest among the less educated, the younger aged and white British women. ${ }^{7}$ This data add to reports of poor reach of incentive interventions, particularly to the most marginalised individuals. ${ }^{12}{ }^{13}$ Universal incentives were preferred to incentives targeted at low-income women, with concerns about unintended consequences such as 
stigma and value judgements raised in linked qualitative data. ${ }^{16}$ Differential uptake across educational groups and the potential for health inequalities to increase is a concern, as noted for lifestyle behaviour change interventions. ${ }^{22}$ Any assumption that incentives might redistribute resources and/or help to reduce health inequalities requires further testing.

Women's disagreement with incentive strategies is particularly problematic due to the onus currently placed on women by health services and governments to change their health-related behaviours. Similar disagreement with paying women to stop smoking in pregnancy was reported for a convenience sample of pregnant women attending an Australian antenatal clinic. ${ }^{23}$ Some understanding of women's disagreement with shopping voucher incentives for individual or household behaviour change, which may seem counter-intuitive, is revealed in narratives of blame, pressure and stigma. ${ }^{16} 2425$ In addition, psychological theory suggests that providing extrinsic motivation through financial incentives alone might be insufficient and meet with resistance, with intrinsic motivation required for more sustained behaviour change. ${ }^{26} \quad 27$ Qualitative data from this study highlight that the real life barriers and facilitators to living healthy lives need to be addressed concurrently with incentive interventions to optimise the likelihood of effectiveness. ${ }^{16}$ For example, current smokers who reported failed attempts to stop were more likely to agree with shopping voucher incentives for a smoke-free home, but disagree with providing vouchers if the mother continues to abstain from smoking after birth. This fits with the evidence on relapse being associated with whether the partner and/or social network of a pregnant woman smokes. ${ }^{28}$ Similarly, linked qualitative data suggest that a free breast pump is perceived to address more intrinsic and extrinsic barriers to continued breast feeding than shopping vouchers, such as overcoming embarrassment with performing in public; resuming social lives; sharing the feeding-bonding experience with partners and relieving the mother as the sole supplier on demand. ${ }^{16}$ However, breast pumps are an uncertain proxy outcome as the relationship between characteristics, use and feeding outcomes are uncertain. ${ }^{29}$

Robust randomised controlled trials reporting reach, impact on health inequalities, ethnic groups, experience outcomes and any unintended consequences, in addition to the target behaviours, are required prior to any implementation or introduction of policy decisions around incentive interventions for smoking cessation in pregnancy, or breast feeding.

\section{Author affiliations}

${ }^{1}$ Nursing, Midwifery and Allied Health Professions Research Unit, University of Stirling, Stirling, UK

${ }^{2}$ Health Services Research Unit, University of Aberdeen, Aberdeen, UK

${ }^{3}$ Ipsos MORI Scotland, Edinburgh, UK

${ }^{4}$ Maternal and Infant Nutrition and Nurture Unit, University of Central Lancashire, Preston, UK

${ }^{5}$ Health Policy and Social Marketing, University of Stirling, Stirling, UK

${ }^{6}$ Health Economics Research Unit, University of Aberdeen, Aberdeen, UK
Acknowledgements The authors would like to thank our coapplicants and research team: Mastrick Café Crèche, Aberdeen and St Cuthbert's and Palatine Children's Centre, Blackpool. Shelley Farrar and Nicola Crossland contributed to the survey design. Grant co-applicants Professor Fiona Dykes, Professor David Tappin and Dr Falko Sniehotta for their collaboration and input to the overall BIBS study design. They also thank the members of the public, the women, families and staff from health services, local government, voluntary sector and other organisations, who generously provided their time by participating in the BIBS study. Other members of the BIBS study team, in particular, Fiona Stewart and Cynthia Fraser for providing guidance with literature searching and reference management; Lara Kemp for providing secretarial support

Contributors PH wrote the first draft of this paper and led the BIBS study. All coauthors have contributed to the design, analysis and paper writing and meet the ICMJE criteria for authorship. HM coordinated service user coapplicant mother and baby group involvement in Aberdeen; contributed to the survey design, piloting, analysis decisions and wrote the first draft of the results. GM led the statistical analysis of the survey data and contributed to writing the methods and results sections. GT coordinated service user coapplicant mother and baby group involvement in Blackpool and contributed to the survey design, piloting and reporting of the results. LB contributed to the survey design and reporting of the results. KS, Lorraine Murray and their colleagues at Ipsos MORI, contributed to the survey design, collected the survey data, and provided the data as an SPSS file for further analysis. AL contributed to the survey design and, with DY, analysed the incentive value and targeting questions in the survey and reported these sections of the results. MKC provided methodological and statistical input to the survey design, analysis and reporting of results.

Funding This project was commissioned by the NIHR Health Technology Assessment Programme (10/31/02) and will be published in full in Health Technology Assessment. Further information including the protocol is available at: http://www.nets.nihr.ac.uk/projects/hta/103102. This report presents independent research commissioned by the National Institute for Health Research (NIHR). The Nursing, Midwifery and Allied Health Professions Research Unit, University of Stirling, the Health Services Research Unit, and Health Economics Research Unit, Institute of Applied Health Sciences, University of Aberdeen are all core-funded by the Chief Scientist Office of the Scottish Government Health and Social Care Directorates.

Competing interests LB has non-financial interests that may be relevant to the submitted work. Ipsos Mori were commissioned to work with the research team by the University of Aberdeen.

Ethics approval Full ethical approval for this study, including service user involvement, was obtained from the North of Scotland Research Ethics Committee (NOSRES, reference number: 12/NS/0041, 12th April 2012) and the BUSH (Built \& Natural Environment, Sport and Health) Ethics Committee, University of Central Lancashire (BUSH064, 8th May 2012).

Provenance and peer review Not commissioned; externally peer reviewed.

Data sharing statement The full dataset is available from the corresponding author: p.m.hoddinott@stir.ac.uk.

Open Access This is an Open Access article distributed in accordance with the Creative Commons Attribution Non Commercial (CC BY-NC 4.0) license, which permits others to distribute, remix, adapt, build upon this work noncommercially, and license their derivative works on different terms, provided the original work is properly cited and the use is non-commercial. See: http:// creativecommons.org/licenses/by-nc/4.0/

\section{REFERENCES}

1. Diepeveen S, Ling T, Suhrcke M, et al. Public acceptability of government intervention to change health-related behaviours: a systematic review and narrative synthesis. BMC Public Health 2013;13:756.

2. Park JD, Mitra N, Asch DA. Public opinion about financial incentives for smoking cessation. Prev Med 2012;55(Suppl):S41-5.

3. Promberger M, Dolan P, Marteau T. 'Pay them if it works': discrete choice experiments on the acceptability of financial incentives to change health related behaviour. Soc Sci Med 2012;75:2509-14 
4. Thomson G, Dykes F, Hurley M, et al. Incentives as connectors: insights into a breastfeeding incentive intervention in a disadvantaged area of North-West England. BMC Pregnancy Childbirth 2012;12:22.

5. Jeffery RW. Financial incentives and weight control. Prev Med 2012;55(Suppl):S61-7.

6. Marmot M. Fair society, healthy lives: the Marmot review. Strategic review of health inequalities in England post 2010. http://www. marmotreview.org/ (accessed Mar 2014).

7. McAndrew F, Thompson J, Fellows L, et al. Infant feeding survey 2010. http://www.hscic.gov.uk/catalogue/PUB08694/ifs-uk-2010-sum.pdf (accessed Mar 2014).

8. Buck D, Frosini F. Clustering of unhealthy behaviours over time: implications for policy and practice. London: The Kings Fund, 2012.

9. Chamberlain C, O'Mara-Eves A, Oliver S, et al. Psychosocial interventions for supporting women to stop smoking in pregnancy. Cochrane Database Syst Rev 2013(10):CD001055.

10. Higgins ST, Washio Y, Heil SH, et al. Financial incentives for smoking cessation among pregnant and newly postpartum women. Prev Med 2012;55(Suppl):S33-40.

11. Hoddinott $\mathrm{P}$, Hislop J, Morgan $\mathrm{H}$, et al. Incentive interventions for smoking cessation in pregnancy: a mixed methods evidence synthesis. Lancet 2012;380(Suppl 30):S48.

12. Radley A, Ballard P, Eadie D, et al. Give it up for baby: outcomes and factors influencing uptake of a pilot smoking cessation incentive scheme for pregnant women. BMC Public Health 2013;13:343.

13. Schmidt H, Voigt K, Wikler D. Carrots, sticks, and health care reform —problems with wellness incentives. N Engl J Med 2010;362:e3.

14. Renfrew MJ, McCormick FM, Wade A, et al. Support for healthy breastfeeding mothers with healthy term babies. Cochrane Database Syst Rev 2012(5):CD001141.

15. Hoddinott P, Seyara R, Marais D. Global evidence synthesis and UK idiosyncrasy: why have recent UK trials had no significant effects on breastfeeding rates? Matern Child Nutr 2011;7:221-7.

16. Morgan $\mathrm{H}$, Hoddinott $\mathrm{P}$, Thomson $\mathrm{G}$, et al. Benefits of incentives for breastfeeding and smoking cessation in pregnancy (BIBS): a mixed methods study to inform trial design. [in press]. Health Technol Assess 2014. http://www.nets.nihr.ac.uk/projects/hta/103102 (accessed Mar 2014).
17. Eunson J, Murray L. The acceptability of carrots. Edinburgh: Ipsos MORI Scotland, 2012. http://www.ipsos-mori.com/newsevents/ca/ 1233/The-acceptability-of-carrots.aspx (accessed Mar 2014).

18. Raab G. Technical Annex to Davidson S., Martin C., Treanor S. Scottish Environmental Attitudes and Behaviours Survey 2008: Technical Report Scottish Executive. 2009. http://www.scotland.gov.uk/Resource/Doc/ 265441/0079493.pdf (accessed Jun 2014).

19. Morgan $H$, Hoddinott $P$, Thomson $G$, et al. Service user groups as co-applicants on a platform study for a trial. Trials 2013;14(Suppl 1):O35

20. Higgins TM, Higgins ST, Heil SH, et al. Effects of cigarette smoking cessation on breastfeeding duration. Nicotine Tob Res 2010; 12:483-8.

21. Kendzor DE, Businelle MS, Costello TJ, et al. Breast feeding is associated with postpartum smoking abstinence among women who quit smoking due to pregnancy. Nicotine Tob Res 2010;12:983-8.

22. Jepson R, Harris F, Platt S, et al. The effectiveness of interventions to change six health behaviours: a review of reviews. BMC Public Health 2010;10:538.

23. Lynagh M, Bonevski B, Symonds I, et al. Paying women to quit smoking during pregnancy? Acceptability among pregnant women. Nicotine Tob Res 2011;13:1029-36.

24. Ingall G, Cropley M. Exploring the barriers of quitting smoking during pregnancy: a systematic review of qualitative studies. Women Birth 2010;23:45-52.

25. Hoddinott $P$, Craig LCA, Britten J, et al. A serial qualitative interview study of infant feeding experiences: idealism meets realism. BMJ Open 2012;2:e000504.

26. Frey B. Not just for the money. An economic theory of personal motivation. Brookfield, VT: Edward Elgar Publishing, 1997.

27. Deci EL, Koestner R, Ryan RM. A meta-analytic review of experiments examining the effects of extrinsic rewards on intrinsic motivation. Psychol Bull 1999;125:627-68.

28. Graham $\mathrm{H}$, Sowden $\mathrm{A}$, Flemming $\mathrm{K}$, et al. Using qualitative research to inform interventions to reduce smoking in pregnancy in England: a systematic review of qualitative studies. Public Health Research Consortium, 2012

29. Becker GE, Cooney F, Smith HA. Methods of milk expression for lactating women. Cochrane Database Syst Rev 2011(12): CD006170. 